\title{
1 Addressing tagging location bias to assess space use by marine 2 animals
}

3

4 Graeme C. Hays ${ }^{1 *}$, Alex Rattray ${ }^{1}$, Nicole Esteban ${ }^{2}$

5

$6{ }^{1}$ Deakin University, Geelong, Victoria, Australia

7 2Department of Biosciences, Swansea University, Swansea SA2 8PP, Wales, UK

8

$9 \quad *$ Correspondence: g.hays@deakin.edu.au

11 Abstract:

12 1. Estimates of space use derived from animal tracking studies are often biased by where animals are tagged, with areas distant to the tagging site, in both space and time, being under-represented.

2. We develop an approach to overcome this tagging bias by quantifying the likely movements of animals after tags have failed.

17 3. We illustrate the approach using high accuracy Fastloc-GPS tracking data for 35 adult female green turtles (Chelonia mydas) equipped with satellite tags within one of the world's largest marine protected areas (MPAs), the British Indian Ocean Territory MPA.

4. Individuals migrated up to $5127 \mathrm{~km}$ from the tagging site, breaking migration distance records for this species. For 28 of 35 individuals travelling to foraging locations well outside the MPA, we estimated that they spent, on average, $9.8 \%$ of their adult lives within the British Indian Ocean Territory MPA.

5. Synthesis and applications. The importance of the British Indian Ocean Territory MPA as a nesting sanctuary for individuals from across an ocean basin is highlighted. The general approach we outline can be applied to a broad range of taxa, including marine mammals, 
fish and sea turtles and will allow unbiased estimates of how important areas, such as MPAs, are used.

Keywords. Migration, Argos, space use, megafauna, telemetry, biologging, Chagos Archipelago

Running head. Tagging location bias and space use

\section{INTRODUCTION}

37 It is now commonplace to track animals to assess their patterns of movement and space use (Costa et al. 2012; Hussey et al. 2015; Kays et al. 2015), with tracking data often providing information that has translated into conservation management and policy (Hays et al. 2019). In many studies, however, space use estimates are influenced by the tagging locations. Put simply, space use estimates will often show tagging sites as high use areas simply because all of the tracks radiate from that location and not because animals necessarily spend lots of time at that tagging site. So, for example, if an animal had instead been tagged in another part of its range, then a different pattern of space use would be generated. Examples of where animals tend to be tagged in only part of their range are widespread across studies and include tagging animals at breeding sites, e.g. turtles, seabirds and pinnipeds, or for fish where they are captured in commercial fisheries (e.g. McMahon et al. 2008; Bailey et al. 2012). Some studies across marine taxa, including sharks, fish, cetaceans, pinnipeds, sea birds and turtles, have tried to correct for tagging location biases, with tracking locations being inversely weighted by when they were recorded in relation to the tagging date, so that locations obtained a long time after tagging are

51 given more weight and vice versa (Block et al. 2011; Queiroz et al. 2019). This elegant approach

52 partly ameliorates tagging location biases, but is not a perfect solution to the problem since 53 animals may continue to move far away from the tagging locations well after the tags fail. Given 54 the widespread issue with tagging location bias, here we conceptualize a new approach to 
tackle this issue. Our approach will be broadly applicable across taxa, allowing unbiased estimates of how species use key areas such as Marine Protected Areas (MPAs). As a case

57 study, we implement the approach using long-term satellite tracking data obtained from a species that can migrate 1000 s of $\mathrm{km}$ across an ocean basin between breeding and foraging 59 sites.

\section{METHODS}

We first developed a conceptual framework for estimating space use in a way that is not biased by the release location of tagged animals. To develop this framework we used three examples from the literature of animals where empirical tracking results of individuals generally only cover part of an individual's overall movements. For illustrative purposes, we selected one fish, one marine mammal and one sea turtle to show the broad applicability of our framework. In each example, we also show how the overall pattern of movements may be broadly known using a range of data-sets that supplement the information provided by tracks of individuals. We then develop this conceptual framework in a case study to estimate use of a large MPA by a long-distance ocean migrant. We use satellite tracking results for green sea turtles (Chelonia mydas) equipped while nesting on the island of Diego Garcia in the Chagos Archipelago, Indian Ocean $\left(7.428^{\circ} \mathrm{S}, 72.458^{\circ} \mathrm{E}\right)$. This nesting area lies at the heart of one of the world's largest protected areas: the British Indian Ocean Territory (BIOT) MPA, that extends generally 200 nautical miles seaward from the outermost atolls to the limit of the UK territorial waters. During the nesting seasons in 2012, 2015, 2017 and 2018, female turtles were located while they were nesting ashore at night. Once turtles were returning to the sea they were restrained in a large open-topped and bottomless wooden box and a Fastloc-GPS Argos tag attached using quick setting epoxy (see Esteban et al., 2017 for details). In 2012, we used two models of satellite tag (SPLASH10-BF, Wildlife Computers, Seattle, Washington $(n=4)$ and model F4G 291A, Sirtrack, Havelock North, New Zealand $(n=4)$. In other years we only used SPLASH10-BF units ( $n=10,5$ and 12 in 2015, 2017 and 2018). Transmitters relayed data via the Argos system (http://www.argos-system.org/) that allowed Fastloc-GPS positions to be 
determined. Only Fastloc-GPS positions obtained with a minimum of four satellites and a residual error value of less than 35 were used, producing locations that were generally within a few tens of meters of the true location (Dujon et al. 2014).

To estimate the proportion of time adult female turtles spend within the BIOT MPA in a way that was free of bias introduced by where and when each animal was tagged or the behaviour of the animal, we supplemented the direct tracking data with other information about the scheduling of migration derived from other sources. The time an adult green turtle spends inside the BIOT MPA can be partitioned across: (i) time spent travelling from the edge of the MPA to and from the nesting beaches at the start and end of the breeding season respectively; (ii) time spent mating, which usually occurs close the nesting beaches; (iii) time spent laying several clutches of eggs. Each of these three periods can be estimated for both male and female turtles. We estimated "(i)" for male and female turtles using our tracking data for turtles leaving the MPA, assuming that the reciprocal journey from the boundary of the MPA to the nesting beaches took the same amount of time. (ii) The amount of time that females spend mating has been estimated at 30 days by using visual observations of green turtles at mating areas (Godley et al. 2002). Male turtles arrive to breed before females and their length of residency at the breeding grounds has been measured at 75 days (Schofield et al. 2013). (iii) The length of time females spend laying clutches has been estimated from the attachment of satellite tags to females at the start of the nesting season (Esteban et al. 2017). Green turtles in the Chagos Archipelago lay a mean of 6 clutches with a modal inter-nesting interval of 13 days (Esteban et al. 2017), so that, on average, they spend a total of 65 days nesting.

The interval between breeding seasons (remigration interval) has been recorded for female green turtles in the Indian Ocean using numbered flipper tags that allow a turtle to be identified when they are encountered nesting across different years. At the island of Mayotte, an isolated green turtle rookery in the SW Indian Ocean, the modal remigration interval for females is 3 years (Bourjea et al. 2007). Given differences in their breeding biology, the likely corresponding modal remigration interval for adult male turtles is 2 years (Hays et al 2014a). 


\section{RESULTS}

\subsection{Conceptual framework}

The issue of tagging site bias is illustrated schematically in Figure 1, which shows the movement patterns that may potentially be performed by animals before and after tags fail, i.e. recorded tracks may only cover a fraction of an animal's overall movements. To overcome tagging location biased estimates of space use, one approach is to augment individual tracking data with additional information on animal movement obtained by other means. For example, for some taxa, seasonal occurrence in certain locations may be known from visual direct observations (e.g. cetaceans); the scheduling of movement may be known from mark-recapture studies (e.g. seabirds, sea turtles, pinnipeds and some fish); different individuals may have been tracked in different parts of a species range. Blending these types of data, with the tracks of individuals tagged in focal areas, may help to complete the picture of an animal's likely movements while it was not being directly tracked.

The long-term patterns of movement of different taxa are shown schematically in Figure 1. In each case, the overall scheduling of their movements may be broadly known, but only sections of their breeding journeys are recorded by direct tracking. For example, for southern right whales (Eubalaena australis), some individuals have been equipped with satellite tags in calving areas in southern Australia and New Zealand that, from photo-id records, they are known to return to seasonally, while their seasonal occurrence at foraging areas in the Southern Ocean has been recorded through whaling records (Mackay et al. 2020) (Figure 1a). Northern bluefin tuna (Thunnus thynnus thynnus) have been equipped with either satellite tags or archival loggers in different parts of their range, allowing their overall extent of movement to be pieced together (Block et al. 2005) (Figure 1b). For adult green turtles that nest on Ascension Island in the central Atlantic, both long-term fidelity to nesting beaches and breeding periodicity have been documented by mark-recapture studies (Mortimer and Carr 1987), while elements of their post-nesting migration routes have been recorded by satellite tracking (Luschi 
et al. 1998) (Figure 1c). Viewed in these ways, direct tracking of individuals can be viewed as just one component of the information that can be used to assess their likely patterns of space use, including periods both before and after they were directly tracked.

\subsection{Case Study: green turtles in the Indian Ocean}

For none of the tracked turtles was the round-trip migration from the nesting beaches to the breeding area and back to the nesting beaches recorded, i.e. tracks only covered part of the expected movements of individuals across a breeding cycle. This result is akin to those examples shown in Figure 1. For 33 of the 35 tags, individuals were tracked to their foraging grounds, as indicated by individuals traveling to localized, relatively shallow areas where they remained for several months before tags failed. In two cases tags failed while individuals were still travelling in the open ocean and had not reached their destination. Turtles travelled to a broad range of destinations after the nesting season, with foraging sites identified across the western Indian Ocean (Figure 2). For seven of the 35 tracked turtles (20\% of all tracked individuals) the post-nesting migration was relatively short, with these individuals travelling around $100 \mathrm{~km}$ northwards to their foraging grounds on the Great Chagos Bank and hence these individuals did not leave the BIOT MPA. The other 28 tracked turtles travelled beyond the MPA boundary and for the 26 of these 28 individuals whose foraging area was identified, two travelled to the Maldives, 17 travelled to islands and submerged banks in parts of the Seychelles and Mascarene Plateau, three travelled to Somalia, two to Kenya, one to Madagascar and one to Mozambique (Figure 2a). The maximum migration distance was for an individual that travelled $5127 \mathrm{~km}$ to foraging grounds in southern Mozambique, but long migrations were widespread with 11 individuals travelling $>3000 \mathrm{~km}$ to reach their foraging grounds and 20 travelling $>2000 \mathrm{~km}$. The earliest tag failure occurred 89 days after deployment and the longest lasting tag functioned for 554 days. After 230 days, $50 \%$ of the tags were still functioning. 
For turtles that travelled beyond the boundary of the MPA, the mean time to travel from Diego Garcia to the limit of the MPA was 6.0 days $(n=28$, range $=3.8-9.6$ days, $S D=1.5$ days). So for female green turtles migrating to foraging grounds outside the BIOT MPA, over a 3-year (1095 days) breeding cycle they would be expected to spend on average, (i) 12 days travelling from the edge of the MPA to and from the nesting beaches, (ii) 30 days mating, (iii) 65 days nesting. So the mean proportion of time spent in the MPA is $107 d / 1095 d=0.098$ or $9.8 \%$ (Figure 2b). The corresponding values for male turtles leaving the MPA, is that over a 2-year breeding cycle (730 days) they spend, (i) 12 days travelling from the edge of the MPA to and from the nesting beaches, (ii) 75 days at the breeding grounds and so $87 \mathrm{~d} / 730 \mathrm{~d}=11.9 \%$ of their time inside the MPA per 2-year breeding cycle.

\section{DISCUSSION}

The extent of tagging bias varies across taxa. For some groups this issue may be less of a problem. For example, for some birds small light-based geolocator tags as well as satellite tags have allowed annual roundtrip migrations to be recorded for many species in both marine and terrestrial species (e.g. Shaffer et al. 2006; Clay et al. 2017; Vardanis et al. 2016); while in some studies with fish, individuals have been tracked across multiple years (Lea et al. 2015), so that movement networks can be estimated to define space use (Jacoby et al. 2020). However in many studies, across multiple taxa, tagging bias issues will be important because tags fail before the full extent of an individual's movement has been captured. For example, often fish including sharks, rays and bony fish, are still travelling to new areas when tags fail (Queiroz et al. 2016; Sousa et al. 2016); keeping tags attached to cetaceans for long periods remains challenging (Fossette et al. 2014); pinnipeds shed external tags when they molt so that multiyear tracks are very difficult to obtain (McMahon et al. 2008); sea turtles generally only breed every few years so it is very difficult to track individuals throughout a complete breedingforaging-breeding cycle (Hays \& Hawkes 2018). For all of these taxa the challenge of our approach is to piece together where animals are most likely moving after tags fail. With sea 
turtles, we have shown how the likely pattern of movement can be estimated by combining direct tracking with data derived from other techniques. Likewise for other taxa, including some fish and marine mammals, this same conceptual approach may be applicable, piecing together the likely overall pattern of movement from direct tracking used in conjunction with other sources of information that shed light on the extent and scheduling of movements.

In some cases, such as with pelagic fish, tagging individuals in different parts of their range as well as researchers sharing data from across tracking studies, offers great promise for assessing the overall pattern of species movements (Queiroz et al. 2019). For example, ocean sunfish (Mola mola) in the NE Atlantic have been satellite tagged at their more northerly summer feeding grounds off Ireland as well as more southerly feeding locations off Portugal (Sims et al. 2009, Sousa et al. 2016). So while individual tracks do not record the full extent of their north-south seasonal movements, these seasonal movements can be pieced together from the range of tracks obtained. For some taxa, tracking data can be supplemented with observations that show locations of seasonal residence, such as sightings data for many cetaceans or catch data for many fish. The likely movement of some taxa might also sometimes be assessed if the drivers of their movement patterns can be accurately described. For example, for wide-ranging oceanic foragers, movement models can now include a thermal constraint on movement (e.g. sea surface temperature for marine animals including seabirds) which may underpin seasonal north-south migrations, as well as the likelihood of animals stopping to feed in prey-rich oceanic patches (Lalire \& Gaspar 2019, Pinaud et al. 2005). Empirical tracking data will allow such movement models to be better parameterized allowing, for example, thermal constraints on seasonal poleward movements to be better quantified (e.g. McMahon \& Hays 2006) as well as the probability of straight-line travel versus localized foraging (Bailey et al. 2012; Humphries et al. 2012). In this way, if the pattern of movement can be accurately modelled, then individual space use can be projected across many years (Lalire \& Gaspar 2019). Our approach for estimating how green turtles use a large MPA may have broad conservation relevance. While the exact values for time spent in the BIOT MPA will not apply to other MPAs, the approach we used will still be applicable, i.e. combining direct tracking with other sources of information to estimate how much time individuals spend in protected areas. 
224 Given that many 1000 s of sea turtles have been satellite tracked around the world (Hays \&

225 Hawkes, 2018) and often there is good information on breeding intervals derived from mark-

226 recapture tagging, our approach will have very broad utility across sea turtle species and

227 populations. With regards to the BIOT MPA, since this protected area was declared in 2010 by

228 the UK Government, there has been clear evidence of the conservation benefits for a range of

229 taxa (D'agata et al. 2016). Nevertheless, the legality of the MPA has been challenged (e.g.

230 Appleby 2015 but also recent media articles such as https://www.bbc.com/news/uk-

231 48371388). Our results greatly extend previous preliminary observations from seven tracked

232 green turtles (Hays et al 2014b). We show that most of breeding female green turtles spend the

233 majority of their adult lives outside the BIOT MPA. In other words, the MPA provides a nesting

234 sanctuary for turtles that spend most of their adult lives at foraging sites across the entire

235 western Indian Ocean. This nesting sanctuary is important, as turtles are particularly susceptible

236 to poaching when ashore nesting, as are their eggs in nests. Therefore, the protection of turtles

237 and their nests in the BIOT MPA has likely been a major contributor to the large increases in

238 nesting numbers observed inside the MPA in recent years (Mortimer et al. 2020). Further, the

239 pan-oceanic migrations of green turtles highlight the value of the conservation efforts that are

240 being implemented across very broad spatial scales such as the western Indian Ocean (e.g., .

241 Likewise, the approach we outline could allow unbiased estimates of how a range of marine

242 mammals and fish use important areas such as MPAs, territorial waters of specific countries or

243 important fishing zones. In summary, we suggest that by using tracking data synergistically with

244 other information about the pattern and scheduling of animal movement, space-use estimates

245 that are free of tag bias impacts may be made. Where this approach can be implemented it will

246 allow improved estimates of how animals use protected areas and are exposed to various

247 threats such as fishing activities.

248

249 ACKNOWLEDGEMENTS

250 G.C.H. and N.E. were supported by the Bertarelli Foundation as part of the Bertarelli

251 Programme in Marine Science (BPMS-2017-4). We thank Nestor Guzman and Jeanne Mortimer

252 for invaluable help in the field. All work was approved by Swansea University and Deakin 
253 University Ethics Committees and the British Indian Ocean Territory (BIOT) Administration of

254 the UK Foreign and Commonwealth Office (permits dated 2 Oct 2012, 24 Jun 2015, 18 Jul 2017,

2556 Apr 2018). Thanks to B.S. and R.D. Kirkby for the graphical abstract image.

256

257 AUTHORS' CONTRIBUTIONS

258 G.C.H. conceived the study and led the writing. G.C.H. and N.E. conducted the fieldwork, G.C.H. 259 and A.R. analysed the data. All authors contributed to manuscript editing.

DATA ACCESSIBILITY

262 All the data used in the calculations to avoid tagging bias issues appear within the manuscript.

264 ORCID

265 Graeme C. Hays http://orcid.org/0000-0002-3314-8189

266 Alex Rattray http://orcid.org/0000-0002-8591-6688

267 Nicole Esteban http://orcid.org/0000-0003-4693-7221

\section{REFERENCES}

271 Appleby, T. (2015). The Chagos marine protected arbitration - a battle of four losers? Journal of Environmental Law, 27, 529-540. https://doi.org/10.1093/jel/eqv027.

Bailey, H., Fossette, S., Bograd, S.J., Shillinger, G.L., Swithenbank, A.M., Georges, J-Y., ... Hays, G.C. (2012). Movement patterns for a critically endangered species, the leatherback turtle (Dermochelys coriacea), linked to foraging success and population status. PLOS ONE, 7(5), e36401. https://doi.org/10.1371/journal.pone.0036401

277 Battley, P., Warnock, N., Tibbitts, T., Gill, R.E., Piersma, T., Hassell, C.J., ... Riegen, A.C. (2012). 
lapponica. Journal of Avian Biology, 43, 21-32. https://doi.org/10.1111/j.1600-

048X.2011.05473.x

Block, B.A., Teo, S.L.H., Walli, A., Boustany, A., Stokesbury, M.J.W., Farwell, C.J., ... Williams, T.D. (2005). Electronic tagging and population structure of Atlantic bluefin tuna. Nature, 434, 1121-1127. https://doi.org/10.1038/nature03463

Block, B.A., Jonsen, I.D., Jorgensen, S.J., Winship, A.J., Shaffer, S.A., Bograd, S.J., ... Costa, D.P. (2011). Tracking apex marine predator movements in a dynamic ocean. Nature, 475, 8690. https://doi.org/10.1038/nature10082

Bourjea, J., Frappier, J., Quillard, M., Ciccione, S., Roos, D., Hughes, G., \& Grizel, H. (2007). Mayotte Island: another important green turtle nesting site in the southwest Indian Ocean. Endangered Species Research, 3, 273-282. https://dx.doi.org/10.3354/esr00053

Byrne, M.E., Cortes, E, Vaudo, J.J., Harvey, G.C., Sampson, M., Wetherbee, B.M., \& Shivji, M. (2017). Satellite telemetry reveals higher fishing mortality rates than previously estimated, suggesting overfishing of an apex marine predator. Proceedings Royal Society London B, 284, 20170658. https://doi.org/10.6084/m9.figshare.c.3825508.v1.

Clay, T.A., Phillips, R.A., Manica, A., Jackson, H.A., \& Brooke M. de L. (2017). Escaping the oligotrophic gyre? The year-round movements, foraging behaviour and habitat preferences of Murphy's petrels. Marine Ecology Progress Series, 579, 139-155. https://doi.org/10.3354/meps12244

Costa, D.P., Breed, G.A., \& Robinson, P.W. (2012) New insights into pelagic migrations: Implications for ecology and conservation. Annual Review of Ecology, Evolution, and Systematics, 43, 73-96. https://doi.org/10.1146/annurev-ecolsys-102710-145045 
D'agata, S., Vigliola, L., Graham, N.A.J.,Wantiez, L., Parravicini, V., Villeger, S., ... Mouillot, D. (2016). Unexpected high vulnerability of functions in wilderness areas: evidence from coral reef fishes. Proceedings Royal Society London B, 283, 20160128. https://doi.org/10.1098/rspb.2016.0128

Dujon, A.M., Lindstrom, R.T., \& Hays, G.C. (2014). The accuracy of Fastloc-GPS locations and implications for animal tracking. Methods in Ecology and Evolution, 5, 1162-1169. https://doi.org/10.1111/2041-210X.12286

Esteban, N., Mortimer, J.A., \& Hays, G.C. (2017). How numbers of nesting sea turtles can be over-estimated by nearly a factor of two. Proceedings Royal Society London B, 284, 20162581. https://doi.org/10.1098/rspb.2016.2581

Fossette, S., Heide-Jorgensen, M.P., Jensen, M.V., Kiszka, J., Bernbe, M., Bertrand, N., \& Vely, M. (2014). Humpback whale (Megaptera novaeangliae) post breeding dispersal and southward migration in the western Indian Ocean. Journal of Experimental Marine Biology and Ecology, 450, 6-14. https://doi.org/10.1016/j.jembe.2013.10.014

Godley, B.J., Broderick, A.C., Frauenstein, R., Glen, F., \& Hays, G.C. (2002). Reproductive seasonality and sexual dimorphism in green turtles. Marine Ecology Progress Series, 226, 125-133. https://doi.org/10.3354/meps226125

Hays, G.C., Bradshaw, C.J.A., James, M.C., Lovell, P., \& Sims, D.W. (2007). Why do Argos satellite tags deployed on marine animals stop transmitting? Journal of Experimental Marine Biology and Ecology, 349, 52-60. https://doi.org/10.1016/j.jembe.2007.04.016 
321 Hays, G.C., Mazaris, A.D., \& Schofield, G. (2014a). Different male vs. female breeding periodicity

322

323

324

325

326

327

328

329

330

331

332

333

334

335

336

337

338

339

340

helps mitigate offspring sex ratio skews in sea turtles. Frontiers in Marine Science, 1, 43. https://doi.org/10.3389/fmars.2014.00043

Hays, G.C., Mortimer, J.A., lerodiaconou, D., \& Esteban, N. (2014b). Use of long-distance migration patterns of an endangered species to inform conservation planning for the world's largest marine protected area. Conservation Biology, 28, 1636-1644. https://doi.org/10.1111/cobi.12325

Hays, G.C., \& Hawkes, L.A. (2018). Satellite tracking sea turtles: opportunities and challenges to address key questions. Frontiers in Marine Science, 5, 432.

https://doi.org/10.3389/fmars.2018.00432

Hays, G.C., Ferreira, L.C., Sequeira, A.M.M., Meekan, M.G., Duarte, C.M., Bailey, H., ... Thums, M. (2016). Key questions in marine megafauna movement ecology. Trends in Ecology \& Evolution, 6, 463-475. https://doi.org/10.1016/j.tree.2016.02.015

Hays, G.C., Bailey, H., Bograd, S.J., Bowen, W.D., Campagna, C., Carmichael, R.H., ... Sequeira, A.M.M. (2019). Translating marine animal tracking data into conservation policy and management. Trends in Ecology \& Evolution, 34, 459-473.

https://doi.org/10.1016/j.tree.2019.01.009

Humphries, N.E., Weimerskirch, H., Queiroz, N., Southall, E.J., \& Sims, D.W. (2012). Foraging success of biological Lévy flights. Proceeding National Academy Sciences USA, 109, 71697174. https://doi.org/10.1073/pnas.1121201109 
Hussey, N.E., Kessel, S.T., Aarestrup, K., Cooke, S.J., Cowley, P.D., Fisk, A.T., ... Whoriskey, F.G. (2015). Aquatic animal telemetry: a panoramic window into the underwater world. Science, 348, 1255642. https://doi.org/10.1126/science.1255642

Jacoby, D.M., Ferretti, F., Freeman, R., Carlisle, A.B., Chapple, T.K., Curnick, D.J., ... Block, B.A., (2020). Shark movement strategies influence poaching risk and can guide enforcement decisions in a large, remote Marine Protected Area. Journal of Applied Ecology. https://dx.doi.org/10.1111/1365-2664.13654

Kays, R., Crofoot, M.C., Jetz, W., \& Wikelski, M. (2015). Terrestrial animal tracking as an eye on life and planet. Science, 348, aaa2478. https://doi.org/10.1126/science.aaa2478

Lalire, M., \& Gaspar, P. (2019). Modeling the active dispersal of juvenile leatherback turtles in the North Atlantic Ocean. Movement Ecology, 7, 7. https://doi.org/10.1186/s40462-0190149-5

Lea, J.S.E., Wetherbee, B.M., Queiroz, N., Burnie, N., Aming, C., Sousa, L.L., ... Shivji, M.S. (2015). Repeated, long-distance migrations by a philopatric predator targeting highly contrasting ecosystems. Scientific Reports, 5, 11202. https://doi.org/10.1038/srep11202

Luschi, P., Hays, G.C., Del Seppia, C., Marsh, R., \& Papi, F. (1998). The navigational feats of green sea turtles migrating from Ascension Island investigated by satellite telemetry. Proceedings of the Royal Society B, 265, 2279-2284. https://doi.org/10.1098/rspb.1998.0571

Luschi, P., Hays, G.C., \& Papi, F. (2003) A review of long-distance movements by marine turtles, and the possible role of ocean currents. Oikos, 103, 293-302. https://doi.org/10.1034/j.1600-0706.2003.12123.x 
Mackay, A.I., Bailleul, F., Carroll, E.L., Andrews-Goff, V., Baker, C.S., Bannister, J., ... Childerhouse, S.J. (2020). Satellite derived offshore migratory movements of southern right whales (Eubalaena australis) from Australian and New Zealand wintering grounds. PLOS ONE, 15(5), e0231577. https://doi.org/10.1371/journal.pone.0231577

McMahon, CR., \& Hays, G.C. (2006). Thermal niche, large scale movements and implications of climate change for a critically endangered marine vertebrate. Global Change Biology, 12, 1330-1338. https://doi.org/10.1111/j.1365-2486.2006.01174.x

McMahon, C.R., Field, I.C., Bradshaw, C.J., White, G.C., \& Hindell, M.A. (2008). Tracking and data-logging devices attached to elephant seals do not affect individual mass gain or survival. Journal of Experimental Marine Biology and Ecology, 360, 71-77.

Mortimer, J.A., \& Carr, A. (1987). Reproduction and migrations of the Ascension Island green turtle (Chelonia mydas). Copeia, 1987, 103-113.

Mortimer, J.A., Esteban, N., Guzman, A.N., \& Hays GC (2020). Estimates of sea turtle nesting populations in the south-western Indian Ocean indicate the importance of the Chagos Archipelago. Oryx, 54, 332-343. https://dx.doi.org/10.1017/S0030605319001108

Pinaud, D., Cherel, Y., \& Weimerskirch, H. (2005). Effect of environmental variability on habitat selection, diet, provisioning behaviour and chick growth in yellow-nosed albatrosses. Marine Ecology Progress Series, 298, 295-304. https://dx.doi.org/10.3354/meps298295

Queiroz, N., Humphries, N.E., Mucientes, G., Hammerschlag, N., Lima, F.P., Scales, K.L., ... Sims, D.W. (2016). Ocean-wide tracking of pelagic sharks reveals extent of overlap with longline fishing hotspots. Proceeding National Academy Sciences USA, 113, 1582-1587. https://doi.org/10.1073/pnas.1510090113 
Queiroz, N., Humphries, N.E., Couto, A., Vedor, M., da Costa, I., Sequeira, A.M.M., ... Sims, D.W. (2019). Global spatial risk assessment of sharks under the footprint of fisheries. Nature, 572, 461-466. https://doi.org/10.1038/s41586-019-1444-4

Schofield, G., Scott, R., Dimadi, A., Fossette, S., Katselidis, K.A., Koutsoubas, D., ... Hays, G.C. (2013). Evidence-based marine protected area planning for a highly mobile endangered marine vertebrate. Biological Conservation, 161, 101-109. https://dx.doi.org/10.1016/j.biocon.2013.03.004

Shaffer, S.A., Tremblay, Y., Weimerskirch, H., Scott, D., Thompson, D.R., Sagar, P.M., ... Costa, D.P. (2006). Migratory shearwaters integrate oceanic resources across the Pacific Ocean in an endless summer. Proceeding National Academy Sciences U.S.A., 103, 12799-12802. https://doi.org/10.1073/pnas.0603715103

Sheppard, C.R.C., Ateweberhan, M., Bowen, B.W., Carr, P., Chen, C.A., Clubbe, C., ... Yesson, C. (2012). Reefs and islands of the Chagos Archipelago, Indian Ocean: why it is the world's largest no-take marine protected area. Aquatic Conservation: Marine and Freshwater Ecosystems, 22, 232-261. https://doi.org/10.1002/aqc.1248

Silva, M.A., Prieto, R., Jonsen, I., Baumgartner, M.F., \& Santos, R.S. (2013). North Atlantic blue and fin whales suspend their spring migration to forage in middle latitudes: building up energy reserves for the journey? PLOS ONE, 8, e76507. https://doi.org/10.1371/journal.pone.0076507

Sims, D.W., Queiroz, N., Doyle, T.K., Houghton, J.D.R., \& Hays, G.C. (2009). Satellite Tracking of the World's largest bony fish, the ocean sunfish (Mola mola L.) in the North East Atlantic. 
Journal of Experimental Marine Biology and Ecology, 370, 127-133.

407 https://doi.org/10.1016/j.jembe.2008.12.011

408

409

410

411

412

413

414

415

416

417

418
Sousa, L.L., Queiroz, N., Mucientes, G., Humphries, N.E., \& Sims, D.W. (2016). Environmental influence on the seasonal movements of satellite-tracked ocean sunfish Mola mola in the north-east Atlantic. Animal Biotelemetry, 4, 7. https://doi.org/10.1186/s40317-016-00992

Teitelbaum, C.S., \& Mueller, T. (2019). Beyond migration: causes and consequences of nomadic animal movements. Trends in Ecology \& Evolution, 34, 569-581. https://doi.org/10.1016/j.tree.2019.02.005

Vardanis, Y., Nilsson, J-Å, Klaassen, R.H.G., Strandberg, R., \& Alerstam, T. (2016). Consistency in long-distance bird migration: contrasting patterns in time and space for two raptors. Animal Behaviour, 113, 177-187. https://doi.org/10.1016/j.anbehav.2015.12.014. 


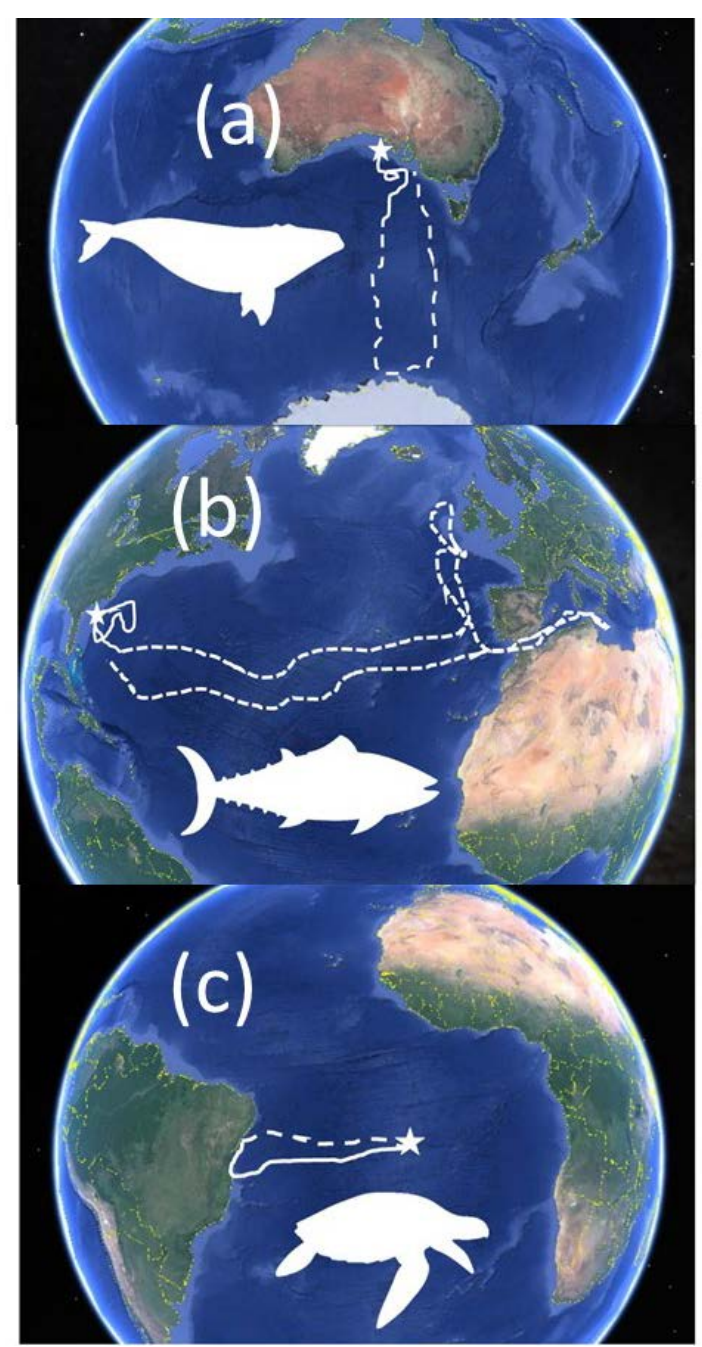

421 FIGURE 1. Schematic representation of how tagging bias may impact estimates of space use in

422 tracking studies. In each case the star represents an assumed tagging site, the solid line the

423 track recorded by a tag and dashed line the possible animal movements after the tag has failed

424 or detached. Icons represent example taxa. Overall patterns of movement, i.e. encompassing

425 the time before, during and after individuals were directly tracked, may be informed by known

426 patterns of seasonal occurrence (e.g. derived from visual observations), mark-recapture studies

427 or by equipping individuals with tracking tags in different parts of a species range. (a) bluefin

428 tuna in the North Atlantic, (b) green turtles nesting on Ascension Island, (c) southern right

429 whales calving off southern Australia. See text for further details. 


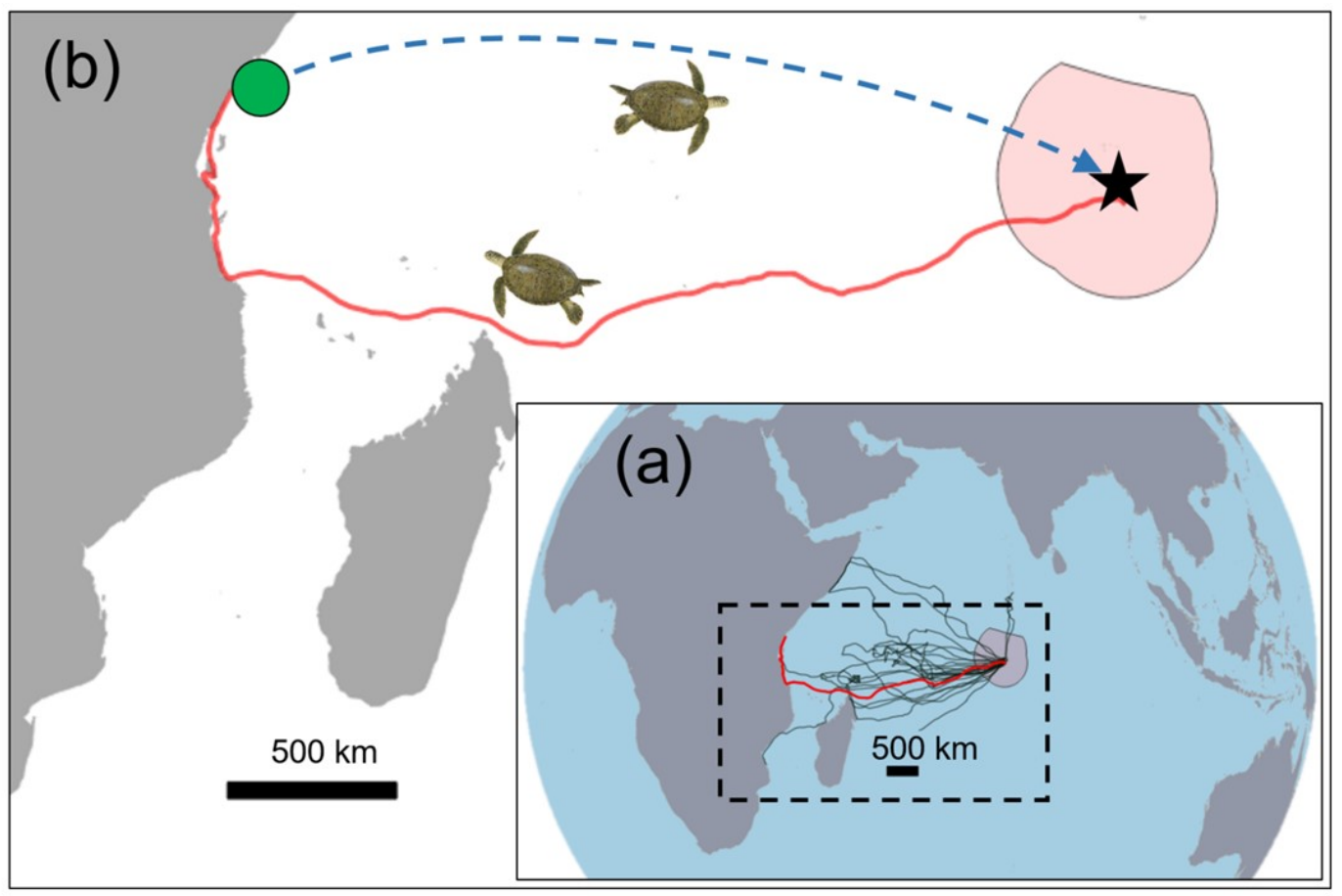

433 FIGURE 2. Case study of estimated space use by migrating green turtles. (a) The tracks of 35

434 green turtles equipped with satellite tags while they were ashore nesting on Diego Garcia in the 435 Chagos Archipelago. The extent of the BIOT MPA is indicated by red shading. Of the 35 tracks, 436 seven travelled to foraging areas inside the MPA on the Great Chagos Bank, 28 travelled outside 437 the MPA of which 26 individuals were tracked all the way to their foraging area. (b) Breeding 438 migration cycle of a female green turtle tracked from a nesting beach on Diego Garcia (black 439 star) to foraging grounds on the coast of Kenya (green circle) from August to November 2015. 440 Fastloc GPS track (solid red line) shows the 105 day, $4835 \mathrm{~km}$ post-nesting migration, and the 3441 yearly (1095 days) return migration inferred from flipper tagging studies is represented by a 442 dashed blue line. Female green turtles spent on average 9.8\% (107 days) of the breeding 443 migration cycle within the BIOT MPA. 